\title{
Gender-specific programming of insulin secretion and action
}

\author{
M C Sugden and M J Holness
}

Department of Diabetes and Metabolic Medicine, Division of General and Developmental Medicine, Barts and the London, Queen Mary's School of Medicine and Dentistry, University of London, Mile End Road, London E1 4NS, UK

(Requests for offprints should be addressed to M J Holness; Email: m.j.holness@qmul.ac.uk)

\begin{abstract}
Insulin secretion and glucose tolerance were studied in 20 -week-old male and female offspring of rat dams maintained on an isocaloric $20 \%$ or $8 \%$ protein diet during pregnancy and lactation after transfer to the same diet at weaning. Protein-restricted male and female offspring were also weaned onto a $20 \%$ protein diet. In males, post-absorptive insulin concentrations were suppressed by protein restriction from conception to adulthood (by $41 \%$; $P<0 \cdot 001$ ); however, basal insulin levels were $2 \cdot 6$-fold higher $(P<0 \cdot 001)$ if protein restriction was limited to gestation and lactation. Post-absorptive insulinaemia in females was unaffected by early or sustained protein restriction, but was lower than for males in the control group and the group exposed to protein restriction during early life alone (by 40\% $(P<0 \cdot 001)$ and $52 \%(P<0 \cdot 001)$ respectively). Plasma insulin/blood glucose ratios were higher in males compared with females in both control and early protein-restricted groups $(1 \cdot 6$-fold $(P<0 \cdot 05)$ and $2 \cdot 3$-fold $(P<0 \cdot 001)$ respectively). A positive linear relationship existed between mean ambient insulin and glucose concentrations in males $(r=1 \cdot 0)$ and females $(r=0.9)$, but the gradient was $12 \cdot 4$-fold greater $(P<0 \cdot 01)$ in males. $\beta$-Cell function was evaluated after intravenous glucose challenge. In males, the acute insulin response and the suprabasal 30-min area under the insulin curve were dramatically higher in rats exposed to protein restriction during gestation and lactation alone $(2 \cdot 6-$ and $2 \cdot 8$-fold respectively; $P<0 \cdot 001)$. In contrast, these parameters were lowered by extending the exposure to protein restriction to adulthood in males, and by either early or prolonged
\end{abstract}

exposure to protein restriction in females. The insulin resistance index was increased $(2.5$-fold; $P<0.001)$ in male, but not female, rats exposed to protein restriction during gestation and lactation alone, and was not increased by extending the period of protein restriction to adulthood in either sex. Thus the data have demonstrated genderspecific lowering of insulin sensitivity due to protein restriction during early life only. The insulinogenic index (insulin response in relation to prevailing glycaemia) was increased in male, but not female, rats exposed to protein restriction during gestation and lactation alone $(3 \cdot 0-$ fold; $P<0 \cdot 001)$. A modest decline in insulin secretion in the female groups exposed to protein restriction until either the end of lactation or adulthood was compensated by increased insulin sensitivity, as demonstrated by significant decreases in the insulin resistance index in both groups (by $48 \%$ and $52 \%$ respectively; $P<0 \cdot 05)$. Glucose disappearance rates did not differ between the male and female control or early protein-restricted groups but were higher in both male $(31 \% ; P<0.05)$ and female groups $(46 \%$; $P<0 \cdot 001)$ exposed to protein restriction from conception to adulthood. Marked gender differences in glucosestimulated insulin secretion were not associated with gender differences with respect to glucose tolerance. Our data therefore demonstrated that exposure to protein restriction during early life alone leads to relative insulin resistance and hyperinsulinaemia in adulthood, but this relationship is gender specific, observed only in males, and glucose tolerance is maintained.

Journal of Endocrinology (2002) 175, 757-767

\section{Introduction}

Sub-optimal fetal growth due to an adverse intrauterine environment, indicated by thinness or low birth weight in term infants, is linked with an increased risk of glucose intolerance, insulin resistance or type 2 diabetes in adult life (reviewed by Phillips 1998). These observations have led to the hypothesis that events occurring before birth caused by malnutrition, or other adverse influences, can lead to persistent changes in organ structure or function that predispose to metabolic disorders in later life (Hales \& Barker 2001). Two major mechanistic hypotheses have been proposed, supported by animal studies, namely maternal malnutrition, in particular protein malnutrition, and prenatal glucocorticoid exposure (Seckl 1998, Holness et al. 2000). In particular, mild protein restriction when imposed during pregnancy or pregnancy and lactation elicits a profound impairment in the structural and functional development of the fetal endocrine pancreas (Dahri et al. 1991) and liver (Desai et al. 1997). Offspring of 
protein-malnourished dams can retain altered levels of expression of hepatic enzymes that play a key role in glucose homeostasis, even after a prolonged period on a normal diet (Desai et al. 1997). Other studies have failed to show persistent alterations in peripheral insulin action that cannot be reversed by switching to a normal diet (Okitolonda et al. 1987, Escriva et al. 1991, PicarelBlanchot et al. 1995, Holness 1996). Many of the features of early protein restriction, including altered hepatic enzyme expression, are mimicked by over-exposure to glucocorticoids during late fetal life (Nyirenda et al. 1998, 2001). In the rat, prenatal glucocorticoid exposure elevates corticosterone levels in later life (Langdown et al. 2001). Moreover, there is a strong association between glucocorticoid receptor expression and the metabolic syndrome (Whorwood et al. 2002), and elevated plasma cortisol concentrations may link low birth weight and the metabolic syndrome (Phillips et al. 1998).

Although it was originally proposed that growth restriction in early life might impact adversely on insulin secretion (Dahri et al. 1991, Martin et al. 1997, Hoet \& Hanson 1999, Fowden \& Hill 2001), most human studies have shown that low birth weight is more strongly associated with impaired insulin action (Phillips et al. 1994a, Clausen et al. 1997, McKeigue et al. 1998). Some studies in humans have failed to show any association between birth weight and $\beta$-cell function (Alvarsson $e t$ al. 1994, Phillips et al. 1994b, Clausen et al. 1997, Martin et al. 1997); others have shown either decreased (Cook et al. 1993) or increased (Hofman et al. 1997) insulin secretion. Many of these studies have been performed in late adulthood, where ageing influences glucose homeostasis and $\beta$-cell function. A recent study of insulin secretion and action in young adulthood, where the prevalence of glucose intolerance is normally very low, has provided important new insights, in particular identifying marked gender differences (Flanagan et al. 2000). Young males who were shorter or lighter at birth were characterised by lower insulin sensitivity but higher insulin secretion and glucose effectiveness, such that overall glucose tolerance was unaffected. In contrast, there was no correlation between birth size and insulin sensitivity in young women. Gender differences have also been reported in animal studies. Desai et al. (1997) reported that ageing male offspring of protein-restricted dams are less glucose tolerant than the non-protein restricted controls, but there is no significant difference for the females.

To explore these gender differences further, the present study examined whether the persistence of the impairment in the insulin secretory response of the pancreas introduced as a consequence of maternal protein restriction during pregnancy and lactation is related to gender. Rat dams were provided with a diet containing $8 \%$ protein (low protein) during pregnancy and lactation. Male and female offspring were separated at weaning. To determine whether any impairment in the insulin secretory response introduced during early life and which persisted into adulthood was dependent on subsequent developmental influences, one group of rats of each sex continued to be maintained on the low-protein diet post weaning (protein restriction; PR) whereas the second was transferred to a standard 20\% protein diet at weaning (early protein restriction; EPR). The control (C) groups comprised male and female offspring of dams maintained on a $20 \%$ protein diet throughout pregnancy and lactation and weaned onto a $20 \%$ protein diet. The insulin secretory and glycaemic responses of the various groups to an intravenous glucose challenge were compared in rats at 20 weeks of age. We selected this study point because previous studies have established that it is possible to detect effects of early life influences at this age (e.g. Holness 1996, Holness \& Sugden 1996). In addition, sampling at this age avoided the effects of ageing that impair glucose homeostasis and $\beta$-cell function which might mask the effects of early life interventions.

\section{Materials and Methods}

\section{Materials}

General laboratory reagents were purchased from Roche Diagnostics (Lewes, East Sussex, UK) or from Sigma (Poole, Dorset, UK). Glucose assay kits were obtained from Roche Diagnostics. Kits for determination of plasma insulin concentrations were from Mercodia (Uppsala, Sweden).

\section{Diets}

Isocaloric diets were prepared (pellet form) by Hope Farms BV, Woerden, The Netherlands (see Sugden \& Holness 1995, Desai et al. 1996, Holness 1996, Holness \& Sugden 1999 for details). The control diet contained approximately $20 \%$ protein (mainly casein) whereas the isocaloric low-protein diet contained $8 \%$ protein by weight. Isocaloricity was maintained by increasing the carbohydrate content (predominantly cerelose) of the proteinrestricted diet (from approximately 63\% to approximately $77 \%$ carbohydrate). Both diets were relatively low in fat (approximately 4\% lipid; soybean oil) by weight.

\section{Animals}

All studies were conducted in adherence to the regulations of the United Kingdom Animal Scientific Procedures Act (1986). Female albino Wistar rats (200-250 g) were purchased from Charles River (Margate, Kent, UK). Adult female Wistar rats were housed in a temperaturecontrolled room $\left(22 \pm 2{ }^{\circ} \mathrm{C}\right)$ on a standard $12 \mathrm{~h}$ light: $12 \mathrm{~h}$ darkness cycle (lights from $0800 \mathrm{~h}$ ). Rats were time-mated by the appearance of sperm plugs (day 0 of pregnancy), 
Table 1 General characteristics of the group. Plasma insulin and blood glucose concentrations were measured in the post-absorptive state using commercial kits. Further details are given in the Materials and Methods section. Data are means \pm S.E.M., with the numbers of rats in parentheses

\begin{tabular}{|c|c|c|c|c|c|c|}
\hline & \multicolumn{2}{|l|}{$\mathrm{C}$} & \multicolumn{2}{|l|}{ EPR } & \multicolumn{2}{|l|}{ PR } \\
\hline & Male & Female & Male & Female & Male & Female \\
\hline Weight (g) & $\begin{array}{c}358 \pm 11 \\
(8)\end{array}$ & $\begin{array}{c}283 \pm 8+† \dagger \\
(10)\end{array}$ & $\begin{array}{c}321 \pm 24^{*} \\
(8)\end{array}$ & $\begin{array}{c}259 \pm 9+\uparrow \dagger \\
(8)\end{array}$ & $\begin{array}{c}258 \pm 9^{* * *} \\
(7)\end{array}$ & $\begin{array}{c}244 \pm 6^{* * *} \\
\text { (7) }\end{array}$ \\
\hline $\begin{array}{l}\text { Plasma insulin } \\
(\mu \cup / m l)\end{array}$ & $\begin{array}{c}15 \pm 2 \\
(6)\end{array}$ & $\begin{array}{c}9 \pm 1+\dagger \\
(10)\end{array}$ & $\begin{array}{c}23 \pm 2^{* * *} \\
(8)\end{array}$ & $\begin{array}{c}11 \pm 1+\dagger \dagger \\
(7)\end{array}$ & $\begin{array}{l}9 \pm 1^{* *} \\
(7)\end{array}$ & $\begin{array}{c}9 \pm 1 \\
(7)\end{array}$ \\
\hline $\begin{array}{l}\text { Blood glucose } \\
(\mathrm{mM})\end{array}$ & $\begin{array}{c}4 \cdot 2 \pm 0 \cdot 2 \\
(8)\end{array}$ & $\begin{array}{c}4 \cdot 1 \pm 0 \cdot 2 \\
(10)\end{array}$ & $\begin{array}{c}4 \cdot 6 \pm 0 \cdot 1 \\
(8)\end{array}$ & $\begin{array}{c}5.3 \pm 0 \cdot 2^{* * *}+\dagger \\
(8)\end{array}$ & $\begin{array}{c}4 \cdot 0 \pm 0 \cdot 3 \\
(7)\end{array}$ & $\begin{array}{c}4 \cdot 6 \pm 0 \cdot 2 \dagger \\
(7)\end{array}$ \\
\hline
\end{tabular}

immediately randomly assigned to either the control or the protein-restricted diets, and maintained on these diets throughout pregnancy and lactation. The provision of the protein-restricted diet did not influence maternal food intake or body weight gain during pregnancy (Sugden \& Holness 1995, Holness \& Sugden 1996). Mean litter sizes were $12 \pm 1(n=7)$ and $11 \pm 1(n=7)$ in control and protein-restricted groups respectively. Any litters containing fewer than 10 pups or more than 15 pups were excluded from the study. Sexes were separated at 26 days after birth. The male and female offspring were then weaned onto the maintenance diet (control or proteinrestricted) with which their mothers had been provided and maintained on this diet until approximately 20 weeks of age. These are termed the $\mathrm{C}$ and $\mathrm{PR}$ groups respectively. A subset of offspring of protein-restricted dams were weaned onto the $20 \%$ diet (EPR group). Offspring were studied at 20 weeks of age. Each data group comprised rats from at least four separate litters.

\section{Intravenous glucose tolerance tests}

For intravenous glucose tolerance tests, each rat was fitted with a chronic indwelling jugular cannula under hypnorm (Janssen Pharmaceuticals Ltd., Oxford, UK) (fentanyl citrate $(0.315 \mathrm{mg} / \mathrm{ml}) /$ fluanisone $(10 \mathrm{mg} / \mathrm{ml}) ; 1 \mathrm{ml} / \mathrm{kg}$ i.p.) and diazepam $(5 \mathrm{mg} / \mathrm{ml} ; 1 \mathrm{ml} / \mathrm{kg}$ i.p) (Phoenix Pharmaceuticals Ltd., Gloucester, UK) anaesthesia at 5-7 days before study. Glucose was administered as an intravenous bolus $(0.5 \mathrm{~g}$ glucose $/ \mathrm{kg}$ body weight; $150 \mu \mathrm{l} / 100 \mathrm{~g}$ body weight) to conscious, unrestrained rats (see Holness \& Sugden 1999). Glucose was injected via a chronic indwelling jugular cannula and blood samples $(100 \mu \mathrm{l})$ were withdrawn at intervals from the indwelling cannula, which was flushed with saline after the injection of glucose to remove residual glucose. Samples of whole blood $(50 \mu \mathrm{l})$ were deproteinised with $\mathrm{ZnSO}_{4} / \mathrm{Ba}(\mathrm{OH})_{2}$, centrifuged $(10000 \mathrm{~g})$ at $4{ }^{\circ} \mathrm{C}$, and the supernatant retained for subsequent assay of blood glucose. The remaining sample was immediately centrifuged $(10000 \mathrm{~g})$ at $4{ }^{\circ} \mathrm{C}$, and plasma was stored at $-20^{\circ} \mathrm{C}$ until assayed for insulin. The acute insulin response (AIR) was calculated as the mean of suprabasal 2- and 5-min plasma insulin. Insulin and glucose responses during the glucose tolerance test were used for calculation of the incremental plasma insulin values integrated over the 30-min period after the injection of glucose (incremental area under the curve; IAUCinsulin; $\Delta \mathrm{I}$ ) and the corresponding incremental integrated plasma glucose values (IAUC-glucose; $\Delta \mathrm{G}$ ). The insulinogenic index $(\Delta \mathrm{I} / \Delta \mathrm{G})$ represents the ratio of these two parameters. The insulin resistance index (IR index) was calculated as the product of the areas under the glucose and insulin curves after glucose challenge. The rate of glucose disappearance was calculated from the slope of the regression line obtained with log-transformed glucose values from 2 to $15 \mathrm{~min}$ after glucose administration and expressed as $\% / \mathrm{min}$.

\section{Statistics}

Results are presented as the mean \pm S.E.M., with the numbers of observations (individual rats) in parentheses. Statistical analysis was by two-way ANOVA (comparing gender and diet) followed by Fisher's post-hoc tests for individual comparisons using StatView (Abacus Concepts, Inc., Berkeley, CA, USA). A $P$ value of $<0.05$ was considered to be statistically significant.

\section{Results}

\section{Effects of protein restriction on body weight}

Protein restriction during fetal development and suckling led to a $14 \%$ reduction in body weight of the 4-day-old neonatal offspring (C, $9 \cdot 8 \pm 0 \cdot 2 \mathrm{~g}(n=8) ; \mathrm{PR}, 8 \cdot 4 \pm 0 \cdot 1 \mathrm{~g}$ $(n=6) ; \quad P<0 \cdot 05)$. Body weight at weaning was also reduced by $22 \%$ by protein restriction $(\mathrm{C}, 43 \cdot 6 \pm 1 \cdot 0$ 
$(n=17) ; \mathrm{PR}, 34 \cdot 0 \pm 0 \cdot 3(n=15) ; P<0 \cdot 001)$. Body weights of the C, PR and EPR rats at 20 weeks of age are shown in Table 1. Protein restriction from conception until adulthood reduced body weight in male and female rats (by $28 \%(P<0 \cdot 001)$ and $14 \%(P<0 \cdot 001)$ respectively). Transfer of protein-restricted rats to control diet at weaning led to recuperative body weight gain. At 20 weeks of age, body weights were $10 \%$ and $8 \%$ lower in EPR versus $\mathrm{C}$ male and female groups respectively. Male $\mathrm{C}$ and EPR groups were significantly heavier $(27 \%$ and $24 \% ; P<0 \cdot 001$ in both cases) than the female C and EPR groups, but there was no significant difference in body weights of male and female PR rats.

\section{General characteristics of the experimental groups}

The age-matched groups were studied in the postabsorptive state at $6 \mathrm{~h}$ after food withdrawal. The general characteristics of the groups are shown in Table 1. In male rats, post-absorptive plasma insulin concentrations were significantly reduced by protein restriction from conception until adulthood (by $40 \%(P<0 \cdot 01)$ compared with the controls) (Table 1). This relative hypoinsulinaemia was accompanied by a trend (not significant) towards a lower ratio of insulin to glucose (an index of relative insulin response to fasting glycaemia) in the male $\mathrm{PR}$ compared with the male $\mathrm{C}$ group (Table 1). In contrast, restricting the period of protein restriction to gestation and lactation resulted in elevated basal insulin levels $(53 \% ; P<0 \cdot 001)$ (Table 1). Due to these effects, post-absorptive plasma insulin concentrations were $2 \cdot 6$-fold higher $(P<0 \cdot 001)$ in the male EPR group compared with the male PR group. Furthermore, there was a significant $(15 \%: \quad P<0 \cdot 05)$ increase in post-absorptive glycaemia in the male EPR group compared with the male PR group.

In female rats, post-absorptive plasma insulin concentrations were unaffected by either sustained or early protein restriction (Table 1). There was a significant $(29 \%$; $P<0.001)$ increase in post-absorptive glycaemia in the female EPR group compared with the female $\mathrm{C}$ group. This effect was not observed in female rats if protein restriction was maintained from conception until adulthood. As a consequence, post-absorptive blood glucose concentrations were $15 \%$ higher $(P<0 \cdot 01)$ in the female EPR group compared with the female PR group.

In the $\mathrm{C}$ and EPR groups, post-absorptive plasma insulin concentrations were significantly lower in females than in age-matched males, by $40 \%(P<0 \cdot 01)$ and $52 \%$ $(P<0 \cdot 001)$ respectively. In contrast, post-absorptive plasma insulin concentrations did not differ between the female and male PR groups. Basal glycaemia did not differ between males and females in the $\mathrm{C}$ group, whereas post-absorptive glycaemia was significantly higher in the female EPR and PR groups than in the male EPR and PR groups (by $15 \%$ in both cases; $P<0.01$ and $P<0 \cdot 05$ respectively). Plasma insulin/blood glucose (I/G) ratios

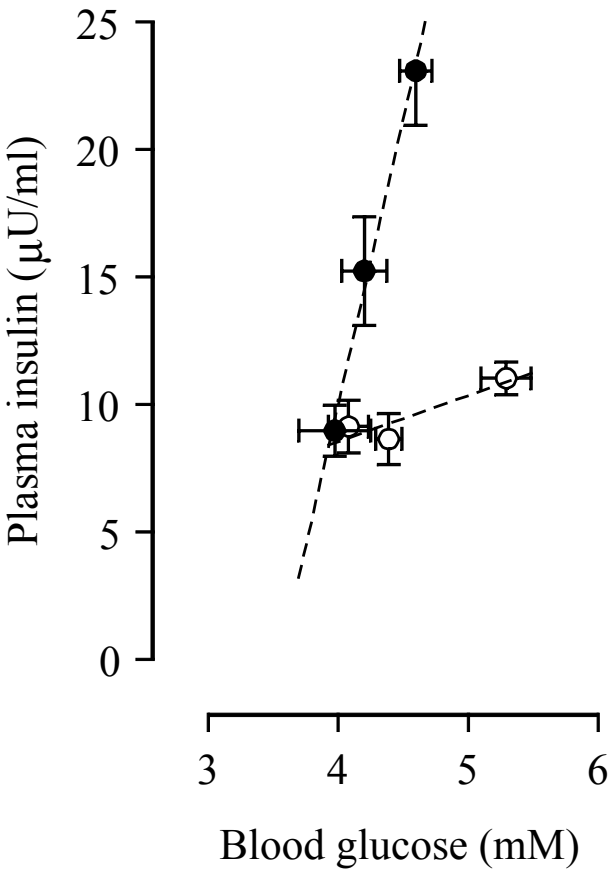

Figure 1 Correlations between mean post-absorbtive blood glucose and mean plasma insulin concentrations in male $(\mathbf{O})$ and female $(O)$ C, PR and EPR rats. Blood samples were withdrawn via a chronic indwelling cannula for measurement of plasma insulin and blood glucose concentrations using commercial kits. Values are means \pm S.E.M. for at least six rats in each group.

were significantly higher in males compared with females in the $\mathrm{C}$ and EPR groups (by 1.4-fold $(P<0 \cdot 05)$ and $2 \cdot 2$-fold $(P<0 \cdot 001)$ respectively), but there was no significant difference in $\mathrm{I} / \mathrm{G}$ ratios between male and female PR rats.

The relationships between post-absorptive mean blood glucose and mean plasma insulin concentrations in the three groups of rats (C, PR and EPR) are shown for males and females in Fig. 1. There was a strong linear relationship between mean blood glucose and mean plasma insulin concentrations in male rats $(r=1 \cdot 0)$ and female rats $(r=0 \cdot 9)$. However, the slope of the line was $12 \cdot 4$-fold greater $(P<0 \cdot 01)$ in the male compared with the female rats.

Insulin secretion after intravenous glucose challenge

To evaluate $\beta$-cell function, plasma insulin concentrations were measured in the three groups of male and female rats at intervals after the administration of an intravenous glucose challenge ( $500 \mathrm{mg} / \mathrm{kg}$ body weight). The pattern of changes in insulin levels induced by intravenous glucose challenge is compared for the various groups in Fig. 2. Plasma insulin concentrations at 2 min after intravenous glucose challenge were significantly higher in the male EPR group than in the male $\mathrm{C}$ and PR groups $(2 \cdot 2$-fold 

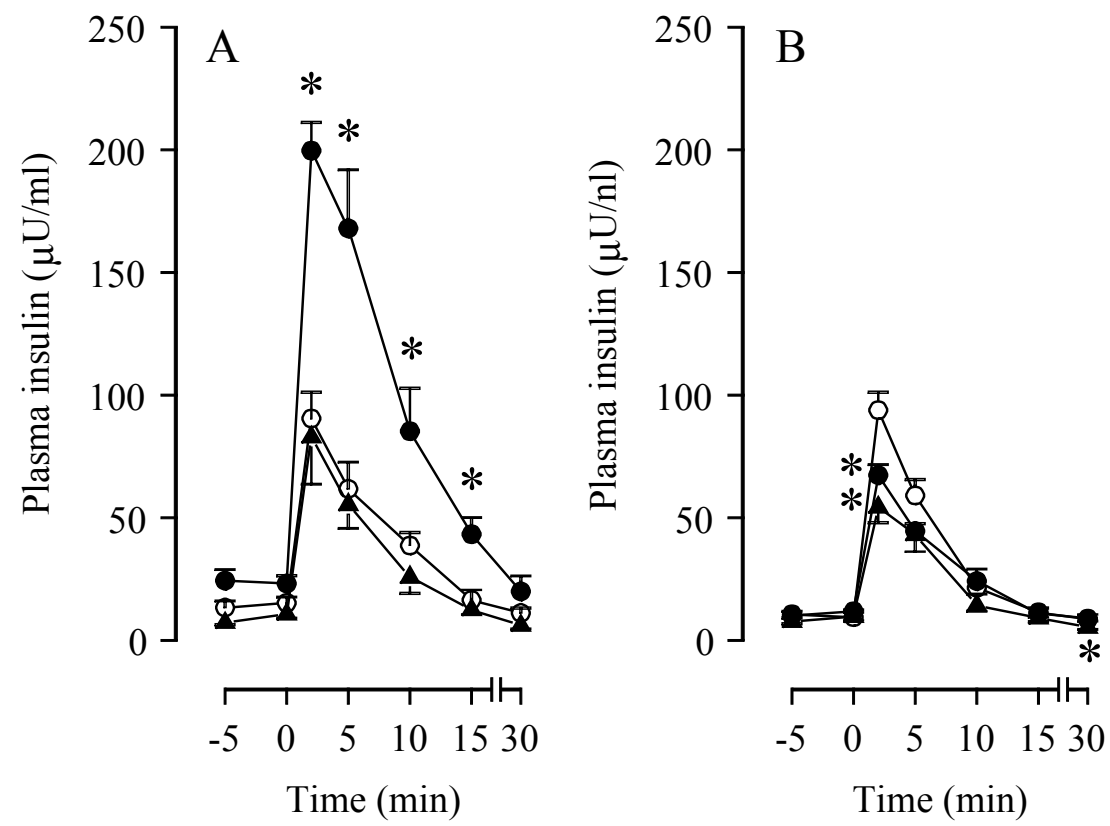

Figure 2 Plasma insulin concentrations after intravenous glucose challenge in male (A) and female $(B)$ rats; $C$ groups $(O)$, EPR groups $(\mathbf{O})$ and PR groups $(\mathbf{\Delta})$. Blood samples were withdrawn at intervals after the administration of glucose as an intravenous bolus $(0.5 \mathrm{~g}$ glucose/kg body weight) for measurement of plasma insulin using a commercial kit. Results are means \pm S.E.M. for at least six rats in each group. Statistically significant differences from $C$ rats are indicated by ${ }^{*} P<0 \cdot 05$. Statistically significant differences between the male and female rats are reported in the text.

and 2-4-fold respectively; $P<0 \cdot 001$ in both cases). Insulin concentrations remained higher in the male EPR group compared with the other two male groups throughout the $30-$ min period of study (Fig. 2). Insulin values at $2 \mathrm{~min}$ after intravenous glucose were significantly lower in the female EPR and PR groups than in the female $\mathrm{C}$ group (by $25 \%(P<0 \cdot 05)$ and $40 \%(P<0 \cdot 01)$ respectively). Insulin concentrations did not differ significantly between the female $\mathrm{C}$ and female EPR groups throughout the remainder of the 30-min period of study. However, insulin concentrations were significantly lower at $30 \mathrm{~min}$ (by $36 \%$; $P<0 \cdot 05)$ in the female PR group compared with the female C group (Fig. 2).

Figure 3 shows the calculated AIR (i.e. the means of suprabasal 2- and 5-min plasma insulin) (Fig. 3A) and total suprabasal 30-min IAUC-insulin $(\Delta \mathrm{I})$ (Fig. 3B) after intravenous administration of glucose $(500 \mathrm{mg} / \mathrm{kg})$ in $\mathrm{C}$, $\mathrm{PR}$ and EPR rats. In male rats, PR did not significantly affect AIR or the IAUC-insulin compared with the C group. By contrast, both AIR and the IAUC-insulin were dramatically higher in male EPR rats compared with male C rats (by 2.6- and 2.8-fold respectively; $P<0 \cdot 001$ in both cases). In female rats, the AIR was significantly lower in PR rats (by 38\%; $P<0.05$ ) compared with $\mathrm{C}$ rats. A modest decline $(26 \%)$ in AIR was also observed in the female EPR group compared with the female C group, but this did not achieve statistical significance. The AIR values (Fig. 3) clearly demonstrated that the early insulin secretory response to intravenous glucose in the male EPR group was higher than that of the female EPR group by $3 \cdot 6$-fold $(P<0 \cdot 001)$. Similarly, the IAUC value for insulin in the EPR group was $3 \cdot 9$-fold $(P<0 \cdot 001)$ higher respectively in males than in females.

Diet-induced changes in insulin secretion can be indicative of altered insulin sensitivity: hyperinsulinaemia is usually considered as a compensatory response to the development of insulin resistance; lowered insulin secretion can indicate enhanced insulin sensitivity. The IR index, the product of the areas under the glucose and insulin curves after glucose challenge, was not significantly affected by sustained protein restriction in male rats (Fig. 4A). However, the IR index was increased by $2 \cdot 5$-fold $(P<0.001)$ in the male EPR group compared with the male $\mathrm{C}$ group. These data demonstrated lowered insulin sensitivity in male rats subjected to early protein restriction that were transferred to the standard diet at weaning. The IR index was significantly decreased in female PR rats compared with female $\mathrm{C}$ rats (by $48 \% ; P<0 \cdot 05$ ). A decline of similar magnitude (48\%) in the IR index was also observed in the EPR group compared with the C group, but this did not achieve statistical significance. IR indices in the $\mathrm{C}$ and $\mathrm{PR}$ groups were similar in the female versus 

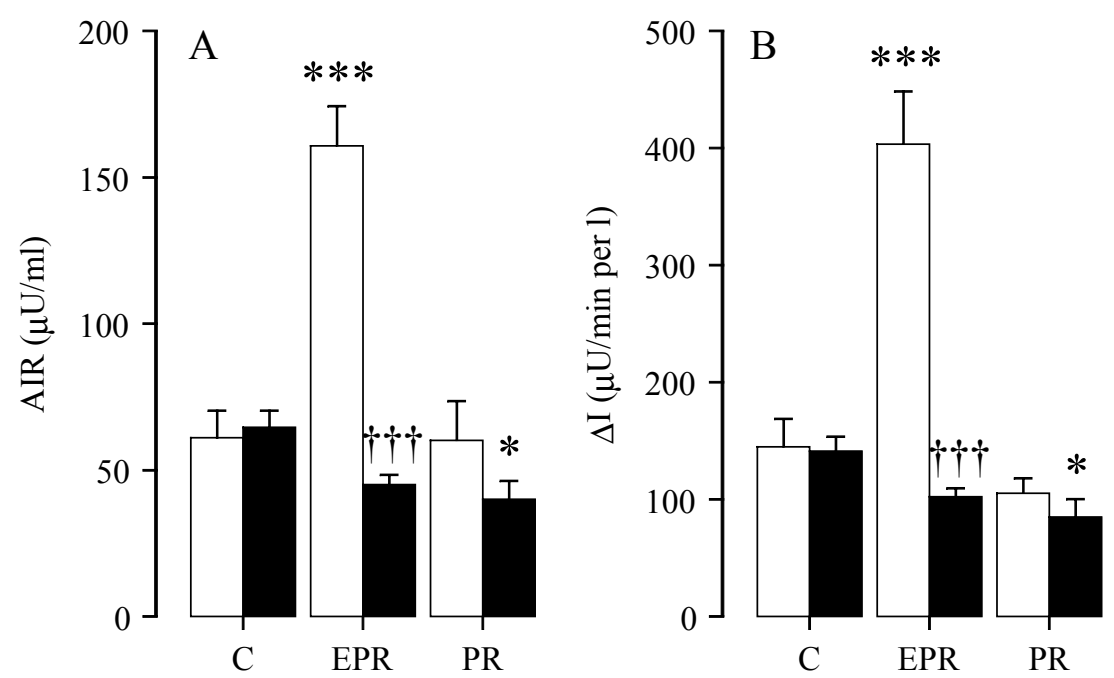

Figure 3 Effects of EPR and PR on the AIR and the IAUC-insulin $(\Delta \mathrm{I})$ after intravenous glucose challenge. Glucose was administered as an intravenous bolus $(0.5 \mathrm{~g}$ glucose $/ \mathrm{kg}$ body weight) to male (open bars) and female (solid bars) C, PR and EPR conscious, unrestrained rats in the post-absorptive state. Blood samples were withdrawn at intervals for measurement of plasma insulin concentrations using a commercial kit. AIR values, calculated as the mean of suprabasal 2- and 5-min plasma insulin, are shown in (A). Insulin responses during the glucose tolerance test were used for calculation of incremental plasma insulin values integrated over the 30-min period after the injection of glucose (IAUC-insulin; $\Delta \mathrm{I}$ ) and are shown in (B). Results are means \pm S.E.M. of at least six rats in each group. Statistically significant differences from control rats are indicated by ${ }^{*} P<0 \cdot 05$; ${ }^{* *} P<0 \cdot 001$. Statistically significant differences between the male and female rats are indicated by ${ }^{+t \dagger} P<0 \cdot 001$.

the male groups. In contrast, the IR index was $4 \cdot 6$-fold higher in male EPR rats compared with female EPR rats $(P<0 \cdot 001)$, indicating that this response was gender specific.

The insulinogenic index $(\Delta \mathrm{I} / \Delta \mathrm{G})$ gives an indication of the overall insulin response in relation to the prevailing level of glycaemia. As shown in Fig. 4B, the male EPR group showed a much greater insulin secretory response to prevailing glycaemia than the male $\mathrm{C}$ (a $3 \cdot 0$-fold increase; $P<0 \cdot 001)$ and PR (a 4.4-fold increase; $P<0 \cdot 001)$ groups. In addition, the responsiveness of insulin secretion to a rise in glycaemia was higher in the male EPR group than in the corresponding female EPR group (a 3-2-fold increase; $P<0 \cdot 001)$. There were no significant differences in insulin sensitivity measured in the three female groups (Fig. 4A).

\section{Intravenous glucose tolerance}

The patterns of changes in glucose observed in vivo after glucose challenge are shown for male rats in Fig. 5A and for female rats in Fig. 5B. Intravenous glucose elevated blood glucose concentrations to approximately $10 \mathrm{mM}$ in the male rats after $2 \mathrm{~min}$. Blood glucose concentrations in the male EPR group were significantly lower than in male $\mathrm{C}$ rats at $2 \mathrm{~min}(10 \% ; P<0 \cdot 05)$, but were significantly higher than in male $\mathrm{C}$ rats at $5 \mathrm{~min}$ (by $13 \% ; P<0 \cdot 05$ ), after intravenous glucose administration. In contrast, blood glucose concentrations in male PR rats were significantly lower than in male $\mathrm{C}$ rats at $15 \mathrm{~min}$ (by $24 \% ; P<0 \cdot 05$ ). Intravenous administration of glucose elevated blood glucose concentrations to approximately $11 \mathrm{mM}$ in the three groups of female rats after 2 min (Fig. 5B). However, significantly lower blood glucose levels were observed in the female PR rats compared with female controls at $10 \mathrm{~min}$ (by $17 \% ; P<0 \cdot 05$ ) and $15 \mathrm{~min}$ (by 25\%; $P<0 \cdot 01$ ) post glucose injection (Fig. 5B). In contrast, significantly higher blood glucose levels were observed in the female EPR rats compared with female control rats at $30 \mathrm{~min}$ (by 33\%; $P<0.05$ ) post glucose injection (Fig. 5B). However, there were no statistical differences between the blood glucose concentrations after intravenous glucose administration in the PR or EPR female groups.

We examined to what extent the altered insulin secretory response to glucose observed in the various groups was accompanied by altered glucose tolerance (Fig. 6). After the glucose load, overall glucose tolerance, as indicated by the integrated glucose area (IAUC), did not differ significantly between the male groups; i.e. C, PR, EPR (Fig. 6A). There was a significantly lower IAUC value (by $23 \% ; P<0.05)$ for glucose in the female EPR group compared with the female C group (Fig. 6A). A similar non-significant trend was observed between female PR and female $\mathrm{C}$ rats. Despite marked gender differences in 

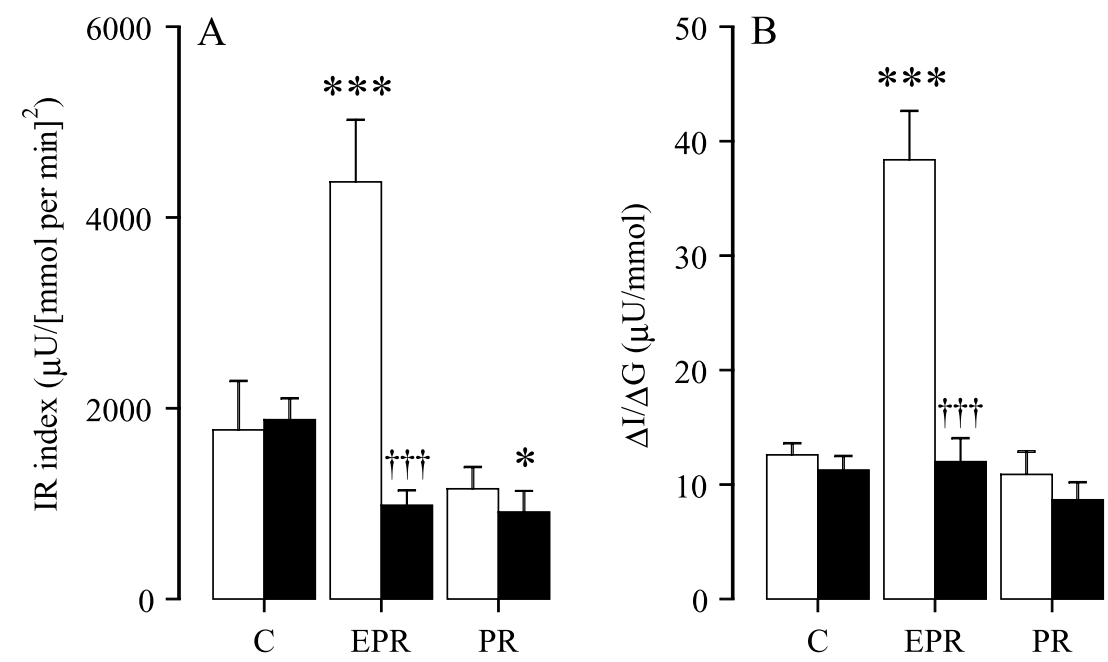

Figure 4 Effects of EPR and PR on the IR index and the insulinogenic index after intravenous glucose challenge. Glucose was administered as an intravenous bolus $(0.5 \mathrm{~g}$ glucose/kg body weight) to male (open bars) and female (solid bars) C, PR and EPR conscious, unrestrained rats in the post-absorptive state. Blood samples were withdrawn at intervals for measurement of plasma insulin and blood glucose concentrations using commercial kits. Insulin and glucose responses during the glucose tolerance test were used for calculation of the incremental plasma insulin values integrated over the 30-min period after the injection of glucose (IAUC-insulin; $\Delta \mathrm{I}$ ) and the corresponding incremental integrated plasma glucose values (IAUC-glucose; $\Delta \mathrm{G}$ ). The IR indices, calculated as the product of these two parameters, are shown in $(\mathrm{A})$. The insulinogenic indices $(\Delta \mathrm{I} / \Delta \mathrm{G})$ represent the ratio of these two parameters and are shown in (B). Values are means \pm S.E.M. for at least six rats in each group. Statistically significant differences from control rats are indicated by ${ }^{*} P<0 \cdot 05 ;{ }^{* *} P<0 \cdot 001$. Statistically significant differences between the male and female rats are indicated by ${ }^{t+t} P<0 \cdot 001$.

insulin secretory responses to glucose, there were no marked gender differences with respect to overall glucose tolerance, as assessed by IAUC for glucose for rats in the C, EPR and PR groups (Fig. 6A).

There was a significant increase $(31 \% ; P<0 \cdot 05)$ in rates of glucose disappearance ( $\mathrm{k}$ values) in the male $\mathrm{PR}$ rats compared with the male $\mathrm{C}$ rats (Fig. 6B). The $\mathrm{k}$ values for glucose did not differ significantly between male EPR rats and male $\mathrm{C}$ rats (Fig. 6B). While the IAUC-glucose value was not significantly altered, the $\mathrm{k}$ value for glucose disappearance calculated over the first 15 min was significantly higher in the female PR rats than in the female $\mathrm{C}$ rats (1.5-fold; $P<0 \cdot 001)$ (Fig. 6B). The female EPR group showed an intermediate $\mathrm{k}$ value. There were no marked gender differences with respect to $\mathrm{k}$ values for rats in any of the nutritional groups.

\section{Discussion}

The present study tested the hypothesis that gender, either through its modulation of growth rate or via intrinsic differences in the characteristics of insulin secretion or action, exerts an important influence on whether glucose intolerance develops as a consequence of early growth retardation. Our data showed that, after early protein restriction, adult male rats have a significantly greater insulin secretory response to glucose than female rats. Maternal protein deprivation followed by maintenance of male offspring on a restricted protein diet lowers the insulin secretory response to glucose, most likely as a consequence of enhanced insulin sensitivity as glucose tolerance is unimpaired. However, transfer of male rats exposed to protein malnutrition during pregnancy and lactation to a standard diet at weaning is no longer associated with enhanced insulin sensitivity in association with lowered insulin secretion. Instead, the insulin secretory response to glucose is greatly augmented to counter the development of insulin resistance. Early protein restriction when maintained post weaning also tends to lower glucose-stimulated insulin secretion in females. However, in females, unlike males, early protein deprivation followed by transfer to a diet containing the normal amount of protein at weaning did not induce compensatory insulin secretion. Our data showed that growth retardation due to maternal protein restriction during pregnancy and lactation is associated with relative insulin resistance and hyperinsulinaemia in young adulthood when offspring are transferred to a normal diet, but this relationship is gender specific in that it is only observed in 

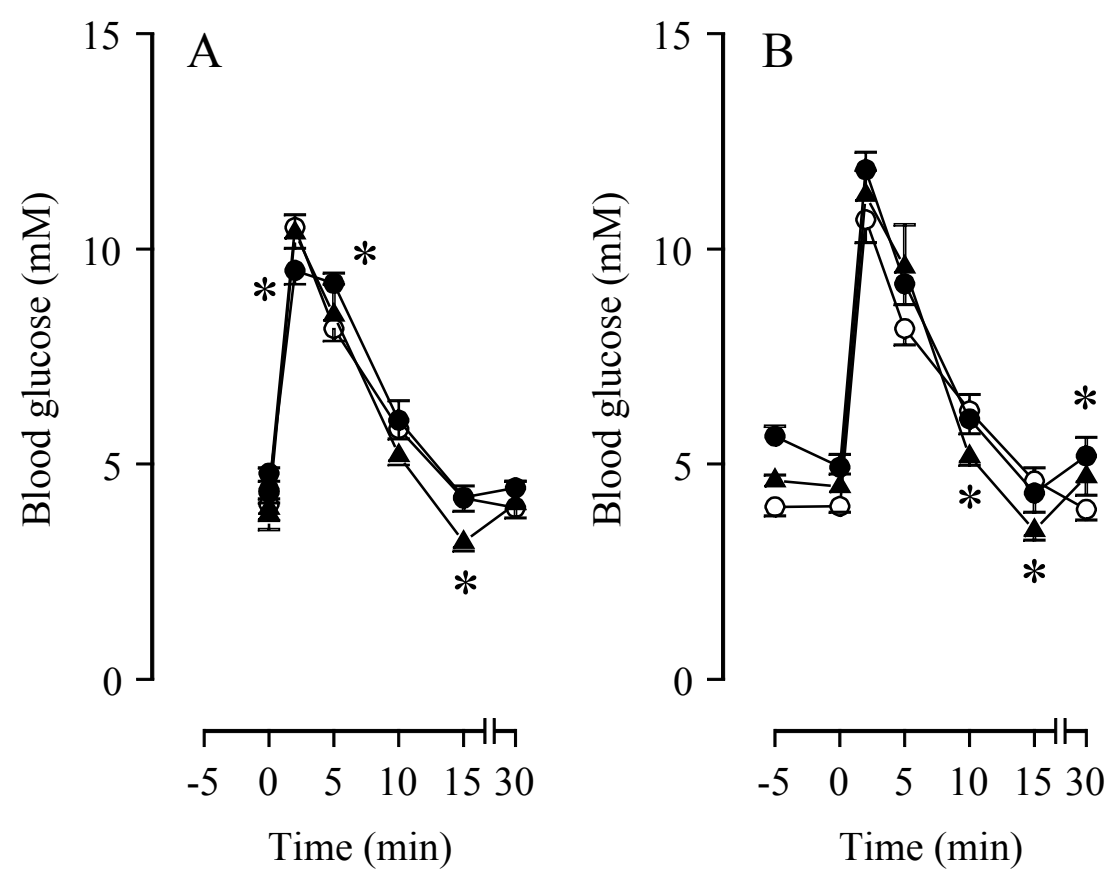

Figure 5 Blood glucose concentrations during an intravenous glucose tolerance test in male $(\mathrm{A})$ and female (B) rats; C groups (O), EPR groups ( $)$ and PR groups $(\mathbf{\Delta})$. Blood samples were withdrawn at intervals after the administration of glucose as an intravenous bolus $(0 \cdot 5 \mathrm{~g}$ glucose $/ \mathrm{kg}$ body weight) for measurement of plasma glucose using a commercial kit. Values are means \pm S.E.M. for at least seven rats in each group. Statistically significant differences from control rats are indicated by ${ }^{*} P<0 \cdot 05$. Statistically significant differences between the male and female rats are reported in the text.

males in this age group. Our data support findings of gender differences in the strength of associations between fetal growth and adult outcomes.

Epidemiological studies indicate that low birth weight in humans is predictive of insulin resistance and diabetes in adulthood (reviewed by Phillips 1998, Hales \& Barker 2001). The molecular mechanisms underlying this link are unknown. However, it has been proposed that environmental factors, including inappropriate maternal nutrition, create an adverse intrauterine environment that may result in permanent changes in insulin secretion and/or action that impair glucose tolerance. In the rat, maternal protein restriction during pregnancy reduces birth weight (Sugden \& Holness 1995, Desai et al. 1996, 1997, Holness 1996, Holness \& Sugden 1999, Ozanne et al. 1999) and thus constitutes an experimental manipulation with which to explore the possible causal relationships between impaired early growth and the later development of impaired glucose tolerance. We examined insulin secretion and glucose tolerance in rats that had experienced early growth retardation through maternal protein restriction from conception to adulthood (PR) or until weaning, followed by switching to a diet containing an adequate amount of protein which permitted recuperative growth (EPR). In male rats, protein restriction from conception to adulthood suppressed post-absorptive insulin and glucose levels, which is indicative of increased insulin sensitivity, and lowered the IR index. By contrast, protein restriction was associated with basal hyperinsulinaemia in male rats whose exposure to protein malnutrition was limited to pregnancy and lactation. However, importantly, the agematched (control) female rats were already characterised by lower post-absorptive insulin levels than the male group, suggesting that female rats are intrinsically more insulin sensitive than male rats. This conclusion was borne out by the responses of male and female rats in the various dietary groups to intravenous glucose challenge. There were no significant differences in the characteristics of glucose tolerance ( $\mathrm{k}$ values, IAUC values for glucose) between male and female rats subjected to protein restriction. Thus, the relative insulin insensitivity of males is amenable to amelioration by modulation of dietary protein content. The data therefore indicated that adult male rats characterised by early growth retardation secondary to protein malnutrition in early life only are intrinsically less insulin sensitive than corresponding female rats, but insulin hypersecretion compensates for the relative impairment of insulin action, thereby maintaining glucose tolerance. In contrast, in adult female rats, protein restriction enhances insulin action, presumably leading to a 

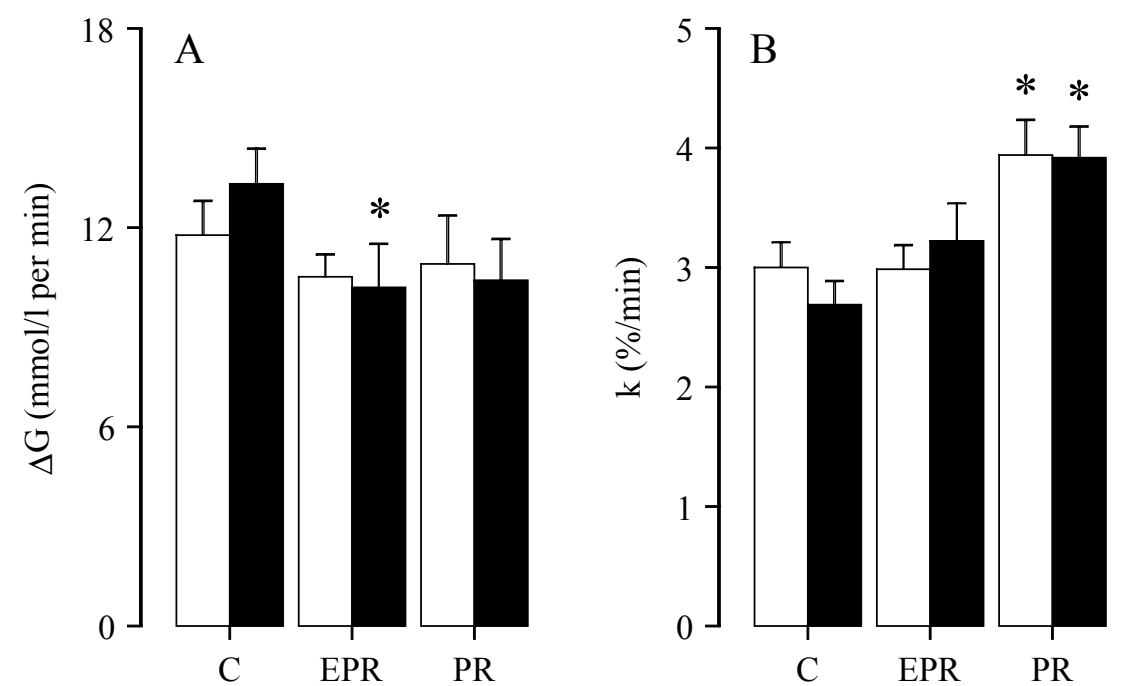

Figure 6 Effects of EPR and PR on the IAUC-glucose $(\Delta G)$ and the rate of glucose disappearance ( $k$ ) after intravenous glucose challenge. Glucose was administered as an intravenous bolus $(0.5 \mathrm{~g}$ glucose/kg body weight) to male (open bars) and female (solid bars) C, PR and EPR conscious, unrestrained rats in the post-absorptive state. Blood samples were withdrawn at intervals for measurement of blood glucose concentrations using a commercial kit. Glucose responses during the glucose tolerance test were used for calculation of the incremental blood glucose values integrated over the 30-min period after the injection of glucose (IAUC-glucose; $\Delta \mathrm{G}$ ) and are shown in (A). Rates of glucose disappearance $(k)$, calculated from the slopes of the regression lines obtained with log-transformed glucose values from 2 to $15 \mathrm{~min}$ after glucose administration and expressed as $\% / \mathrm{min}$, are shown in (B). Values are means \pm S.E.M. for at least seven rats in each group. Statistically significant differences from control rats are indicated by ${ }^{*} P<0 \cdot 05$. There were no statistically significant differences between the male and female rats.

reduced requirement for insulin secretion to maintain normoglycaemia.

Rats maintained on low-protein diets frequently exhibit normal or enhanced glucose tolerance and insulin action (Okitolonda et al. 1987, Escriva et al. 1991, PicarelBlanchot et al. 1995). The present data therefore lend further support to the concept that protein restriction can enhance insulin action, but that this response may be dependent on gender. The comparison of the EPR and PR groups made in the present study permits a critical analysis of the specific effect of protein restriction in early life. Transfer of the male protein-restricted rats to a standard diet at weaning elevated plasma insulin concentrations both in the post-absorptive state and after glucose challenge compared with the age-matched male PR group. An elevated plasma insulin concentration in the post-absorptive state is indicative of insulin resistance and, consistent with this, post-absorbtive hyperinsulinaemia was associated with higher IR indices in the male EPR group. The higher insulin/glucose concentration ratios observed in the male EPR rats before intravenous glucose challenge suggests that significant insulin secretion can occur at a lower level of glycaemia in male EPR rats than in the male PR rats. The significantly higher IAUC values for insulin and $\Delta \mathrm{I} / \Delta \mathrm{G}$ values in the male $\mathrm{EPR}$ rats compared with the male PR group confirms that insulin secretion by the $\beta$-cell is hyper-responsive to glucose in the male EPR group. However, although insulin concentrations were significantly higher, intravenous glucose challenge was associated with normal glucose disappearance rates in the male EPR rats. The data indicated that male rats adapted to protein restriction during their early life respond to transfer to a diet containing the normal amount of protein with a loss of insulin sensitivity compared with PR rats, and this is countered by enhanced insulin secretion.

The gender-specific response to early protein restriction identified in the present study is important in relation to earlier studies showing increased vulnerability of male rats, compared with females, to the later development of obesity (Anguita et al. 1993), hypercholesterolaemia (Lucas et al. 1996) and triacylglycerolaemia (Lucas et al. 1996) as a consequence of early protein restriction. It has been hypothesised that nutritional sensitivity in the males might relate to the faster growth of tissues and hence more critical nutritional needs (Lucas et al. 1996). However, in the present study, there was no indication that the capacity of the $\beta$-cell for insulin secretion was more impaired in 
males than in females as a consequence of early protein restriction. Rather it appears that loss of insulin secretory capacity, should it occur in later life, is more related to the functional demands placed on the endocrine pancreas during adulthood through changes in insulin action.

It cannot be established from the present studies whether the increase in insulin secretion by the $\beta$-cells of the male EPR group is a direct consequence of an attenuated action of insulin, although this might appear likely. However, there was a significant increase in fasting insulin levels in the male EPR group and insulin concentrations after glucose challenge are not decreased. Therefore, deficient insulin production does not play any major role in the development of insulin resistance in the male EPR group, and early growth retardation resulting from protein restriction does not irreversibly impair the insulin secretory capacity of the $\beta$-cell. Indeed, in male young adulthood, the capacity for insulin secretion in response to increased glycaemia is markedly enhanced. It is therefore likely that, with time, relative hypersecretion of insulin - particularly in males - may lead to progressive $\beta$-cell exhaustion and, eventually, impaired insulin secretion may develop making hyperglycaemia and glucose intolerance inevitable.

\section{Acknowledgements}

This study was supported in part by project grants from Diabetes UK (RD01/2249) and the Wellcome Trust (060965/Z/00) to M C S and M J H.

\section{References}

Alvarsson M, Efendic S \& Grill VE 1994 Insulin responses to glucose in healthy males are associated with adult height but not with birth weight. Journal of Internal Medicine 236 275-279.

Anguita RM, Sigulem DM \& Sawaya AL 1993 Intrauterine food restriction is associated with obesity in young rats. Journal of Nutrition 123 1421-1428.

Clausen JO, Borch-Johnsen K \& Pedersen O 1997 Relation between birth weight and the insulin sensitivity index in a population sample of 331 young, healthy Caucasians. American Journal of Epidemiology $14623-31$.

Cook JT, Levy JC, Page RC, Shaw JA, Hattersley AT \& Turner RC 1993 Association of low birth weight with beta cell function in the adult first degree relatives of non-insulin dependent diabetic subjects. British Medical Journal 306 302-306.

Dahri S, Snoeck A, Reusens-Billen B, Remacle C \& Hoet JJ 1991 Islet function in offspring of mothers on low-protein diet during gestation. Diabetes 40 (Suppl 2) 115-120.

Desai M, Crowther NJ, Lucas A \& Hales CN 1996 Organ-selective growth in the offspring of protein-restricted mothers. British Journal of Nutrition 76 591-603.

Desai M, Byrne CD, Zhang J, Petry CJ, Lucas A \& Hales CN 1997 Programming of hepatic insulin-sensitive enzymes in offspring of rat dams fed a protein-restricted diet. American Journal of Physiology. Gastrointestinal and Liver Physiology 272 G1083-G1090.
Escriva F, Kergoat M, Bailbe D, Pascual-Leone AM \& Portha B 1991 Increased insulin action in the rat after protein malnutrition early in life. Diabetologia 34 559-564.

Flanagan DE, Moore VM, Godsland IF, Cockington RA, Robinson JS \& Phillips DI 2000 Fetal growth and the physiological control of glucose tolerance in adults: a minimal model analysis. American Journal of Physiology. Endocrinology and Metabolism 278 E700-E706.

Fowden AL \& Hill DJ 2001 Intra-uterine programming of the endocrine pancreas. British Medical Bulletin 60 123-142.

Hales CN \& Barker DJ 2001 The thrifty phenotype hypothesis. British Medical Bulletin 60 5-20.

Hoet JJ \& Hanson MA 1999 Intrauterine nutrition: its importance during critical periods for cardiovascular and endocrine development. Journal of Physiology 514 617-627.

Hofman PL, Cutfield WS, Robinson EM, Bergman RN, Menon RK, Sperling MA \& Gluckman PD 1997 Insulin resistance in short children with intrauterine growth retardation. Journal of Clinical Endocrinology and Metabolism 82 402-406.

Holness MJ 1996 Impact of early growth retardation on glucoregulatory control and insulin action in mature rats. American Journal of Physiology. Endocrinology and Metabolism 270 E946-E954.

Holness MJ \& Sugden MC 1996 Suboptimal protein nutrition in early life later influences insulin action in pregnant rats. Diabetologia 39 $12-21$.

Holness MJ \& Sugden MC 1999 Antecedent protein restriction exacerbates development of impaired insulin action after high-fat feeding. American Journal of Physiology. Endocrinology and Metabolism 276 E85-E93.

Holness MJ, Langdown ML \& Sugden MC 2000 Early-life programming of susceptibility to dysregulation of glucose metabolism and the development of Type 2 diabetes mellitus. Biochemical Journal 349 657-665.

Langdown ML, Holness MJ \& Sugden MC 2001 Early growth retardation induced by excessive exposure to glucocorticoids in utero selectively increases cardiac GLUT1 protein expression and Akt/protein kinase B activity in adulthood. Journal of Endocrinology 169 11-22.

Lucas A, Baker BA, Desai M \& Hales CN 1996 Nutrition in pregnant or lactating rats programs lipid metabolism in the offspring. British Journal of Nutrition 76 605-612.

McKeigue PM, Lithell HO \& Leon DA 1998 Glucose tolerance and resistance to insulin-stimulated glucose uptake in men aged 70 years in relation to size at birth. Diabetologia 41 1133-1138.

Martin MA, Alvarez C, Goya L, Portha B \& Pascual-Leone AM 1997 Insulin secretion in adult rats that had experienced different underfeeding patterns during their development. American Journal of Physiology. Endocrinology and Metabolism 272 E634-E640.

Nyirenda MJ, Lindsay RS, Kenyon CJ, Burchell A \& Seckl JR 1998 Glucocorticoid exposure in late gestation permanently programs rat hepatic phosphoenolpyruvate carboxykinase and glucocorticoid receptor expression and causes glucose intolerance in adult offspring. Journal of Clinical Investigation 101 2174-2181.

Nyirenda MJ, Welberg LA \& Seckl JR 2001 Programming hyperglycaemia in the rat through prenatal exposure to glucocorticoids - fetal effect or maternal influence? Journal of Endocrinology 170 653-660.

Okitolonda W, Brichard SM \& Henquin JC 1987 Repercussions of chronic protein-calorie malnutrition on glucose homeostasis in the rat. Diabetologia 30 946-951.

Ozanne SE, Wang CL, Dorling MW \& Petry CJ 1999 Dissection of the metabolic actions of insulin in adipocytes from early growth-retarded male rats. Journal of Endocrinology 162 313-319.

Phillips DI 1998 Birth weight and the future development of diabetes. A review of the evidence. Diabetes Care 21 (Suppl 2) B150-B155.

Phillips DI, Barker DJ, Hales CN, Hirst S \& Osmond C 1994a Thinness at birth and insulin resistance in adult life. Diabetologia 37 $150-154$. 
Phillips DI, Hirst S, Clark PM, Hales CN \& Osmond C $1994 b$ Fetal growth and insulin secretion in adult life. Diabetologia 37 592-596.

Phillips DI, Barker DJ, Fall CH, Seckl JR, Whorwood CB, Wood PJ \& Walker BR 1998 Elevated plasma cortisol concentrations: a link between low birth weight and the insulin resistance syndrome? Journal of Clinical Endocrinology and Metabolism 83 757-760.

Picarel-Blanchot F, Alvarez C, Bailbe D, Pascual-Leone AM \& Portha B 1995 Changes in insulin action and insulin secretion in the rat after dietary restriction early in life: influence of food restriction versus low-protein food restriction. Metabolism 44 1519-1526.

Seckl JR 1998 Physiologic programming of the fetus. Clinics in Perinatology 25 939-962.
Sugden MC \& Holness MJ 1995 Modulation of in vivo insulin action by dietary protein during pregnancy. American Journal of Physiology. Endocrinology and Metabolism 268 E722-E729.

Whorwood CB, Donovan SJ, Flanagan D, Phillips DI \& Byrne CD 2002 Increased glucocorticoid receptor expression in human skeletal muscle cells may contribute to the pathogenesis of the metabolic syndrome. Diabetes 51 1066-1075.

Received 22 July 2002

Accepted 6 September 2002 